\title{
Modeling Tetrapodal Nanotube Junctions
}

\author{
Beata Szefler ${ }^{1}$, Mircea V. Diudea ${ }^{2}$ \\ ${ }^{1}$ Department of Physical Chemistry, Collegium Medicum \\ Nicolaus Copernicus University, Kurpińskiego 5 \\ 85-950, Bydgoszcz, Poland \\ e-mail:beatas@cm.umk.pl \\ ${ }^{2}$ Faculty of Chemistry and Chemical Engineering \\ Babes-Bolyai University \\ 400-028 Cluj, Romania
}

(Received: 10 February 2012; accepted: 7 June 2012; published online: 30 August 2012)

\begin{abstract}
Tetrapodal nanotube junction can be modeled by fullerene spanning and by using some operations on map. They can self-assembly in more complex structures, such as dendrimers and/or multi tori, which are structures of high genera. Eight tetrapodal units were designed and their energetics evaluated at the Hartree-Fock HF level of theory. Their stability is discussed in terms of total energy, HOMO-LUMO gap, strain energy, HOMA index of aromaticity and the Kekulé structure count. The results of this study show that the tetrapodal junctions, bearing more aromatic patches, can be a challenge for the laboratory synthesis of new nanostructures.
\end{abstract}

Key words: fullerenes, nanotube junctions, aromaticity, HOMA index, Kekule structure count

\section{INTRODUCTION}

It is well-known that in the synthesis of nanotubes a mixture of nano-structures appears: single- and multiwalled nanotubes, fullerenes, onion-fullerenes and others. It is expected that in the experimental conditions fullerenes can be spanned, thus resulting in open cages of which open-faces can be prolonged by nanotubes of various chirality and tessellation (most probably a hexagonal one). We call such spanned fullerenes (prolonged or not) nanotube junctions. According to their symmetry they can be tetrahedral, octahedral and icosahedral ones.
The tetrahedral/tetrapodal junctions are particularly interesting due to their similarity with the tetrahedral $s p^{3}$ hybridized Carbon atom: the valences are now nanotubes while the atom is an opened cage embedded in a surface of genus 2 (more information about structures of high genera can be found in Refs. [1, 2]). As the single $\mathrm{C}$ atom, a tetrapodal junction can be used to build various nanostructures such as dendrimers and multi tori MT. Figure 1 illustrates the unit named TriPen_T_60A and the dendrimer (at the first generation) resulted by joining the points of connectivity two of five such units. The patch of this unit is called "tripentylene", $\left[6:(0,5)_{3}\right]$.
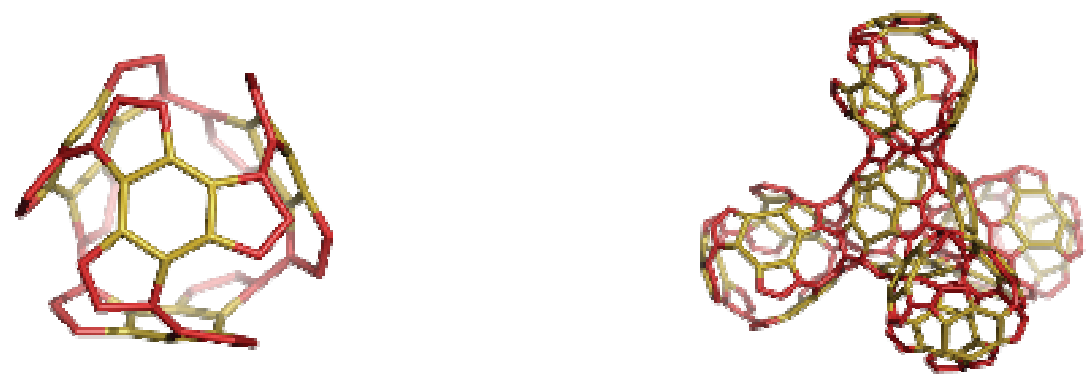

Fig. 1. TriPen_T_60A (left) and its dendrimer (right) 


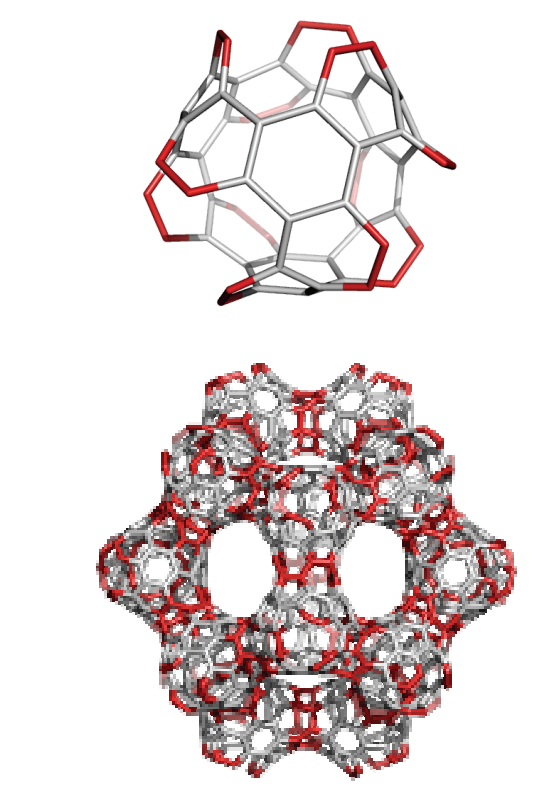

$\operatorname{MT20}(\operatorname{Le}(\mathrm{Op}(\mathrm{Ca}(T)))) ;\left[\mathrm{Op}\left(\mathrm{Ca}_{(3,2) \mathrm{C}}(I)\right)\right]$ $v=20 \times 60 ; e=1740 ; f_{6}=320 ; f_{7}=180 ; g=21$
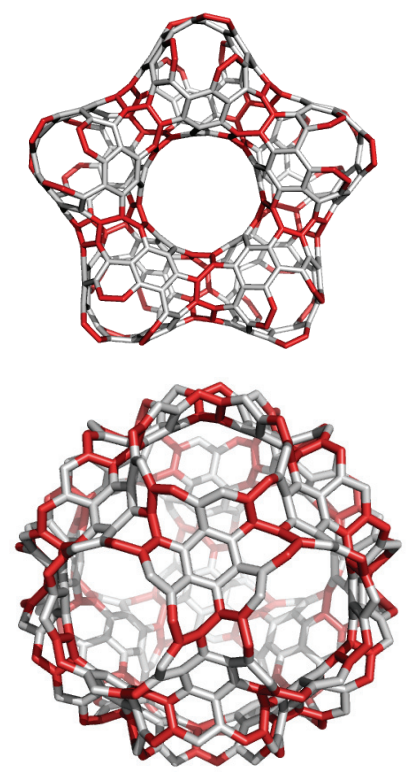

Core $=\mathrm{Op}\left(\mathrm{Ca}_{(3,2) \mathrm{c}}(I)\right)$ $20 \times\left[6:(6,7)_{3}\right]$ $v=420 ; e=570 ; f_{6}=80 ; f_{7}=60 ; g=6$

Fig. 2. Top row: TriPhen_T_60A (left) and a pentagonal hyper-ring(right). Bottom row: Multi-torus MT( $\operatorname{Le}(\mathrm{Op}(\mathrm{Ca}(T)))) ;\left[\mathrm{Op}\left(\mathrm{Ca}_{(3,2) \mathrm{C}}(I)\right)\right]$ (left) and its core (right)

Figure 2 shows the unit TriPhen_T_60A (top, felt), designed by the sequence of map operations: $\operatorname{Le}(\mathrm{Op}(\mathrm{Ca}(\mathrm{T})))$ (or by spanning the $\mathrm{C}_{60}$ fullerene) that can self-arrange to a pentagonal multi torus MT (top, right), comprising five such units.

Next, 12 pentagonal MT can form a supra-structure, called here MT20, with specification of the map operations used to design the repeating unit and with the map operations used to draw the core of this MT20. More about the map operations can be found in Refs. [3-5].

The above supra-dodecahedron shows $g=21$ while its core is $g=6$. Recall, the genus of a (discretized) surface is the number of simple tori comprising that surface. The above repeat unit shows the patch called "triphenylene", $\left[6:(0,6)_{3}\right]$, which shows high aromaticity and stability as well (see below).

\section{STRUCTURE DESIGN}

The hypothetical nanotube junctions discussed herein were designed by using CVNET [6] and NANO STUDIO [7] software programs developed at TOPO GROUP CLUJ. The program CVNET enables modification of a given covering/tessellation, embedded in any surface, according to various operations on maps. The software package
NANO STUDIO enables generation, modification and substructure counting as well as a polynomial description of polyhedral nanostructures. In particular, the assembling of supra-structures from units was done by this program. Figure 3 lists a series of eight tetrapodal nanojunctions with their patch description. The energetics of these units is presented in the next section, in comparison with $\mathrm{C}_{60}$, the reference structure in nanoscience.

\section{STABILITY OF TETRAPODAL NANOTUBE JUNCTIONS}

The stability of junctions was tested based on optimized geometries at Hartree-Fock HF (HF/6-31G**) level of theory. The calculations were performed in gas phase by Gaussian 09 [8], on open-end-hydrogenated structures. As a reference structure, we considered $\mathrm{C}_{60}$, the most referred structure in Nanoscience. Table 1 lists the total energy obtained after optimization of the analyzed structures, the total energy per Carbon atom, $E_{\mathrm{tot}} / \mathrm{C}$ and HOMO-LUMO HL Gap. This test of stability was done to support the idea of various nanotube junctions appearing in real experiments by welding the randomly superposed nanotubes.

One can see that the total energy per Carbon atom is favorable to tetrapodal junction, in comparison to $\mathrm{C}_{60}$, the 


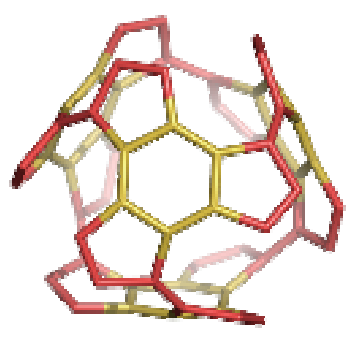

TriPen_T_60A; Patch: $\left[6:(0,5)_{3}\right]-1$ -

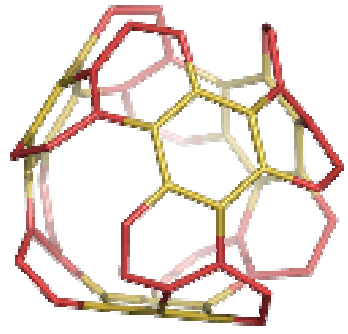

TriPhen_T_60A; Patch: $\left[6:(0,6)_{3}\right]-3-$

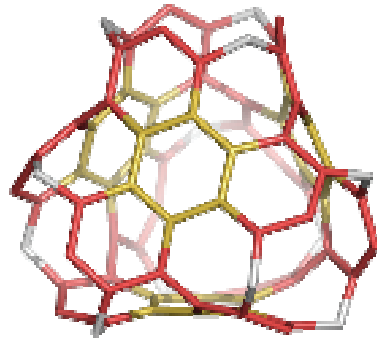

TriPhen_TT_84Z; Patch: [6:(6,7) $]$-5-

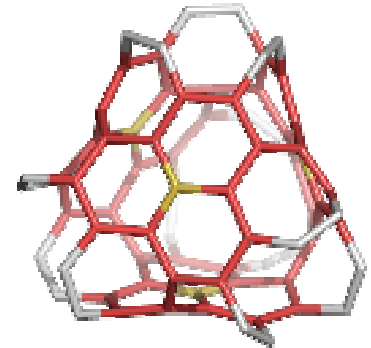

Tri6_T_7_76A; Patch: [1:(6) 3 ] -7-

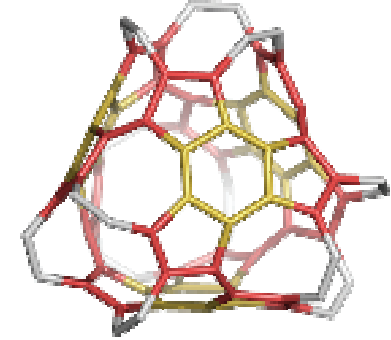

TriPen_TT_84A; Patch: [6:(5,8) 3 -2-

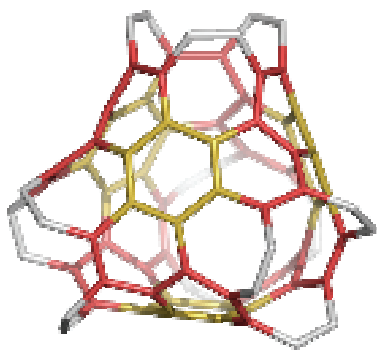

TriPhen_TT_84A; Patch: $\left[6:(6,7)_{3}\right]$-4-

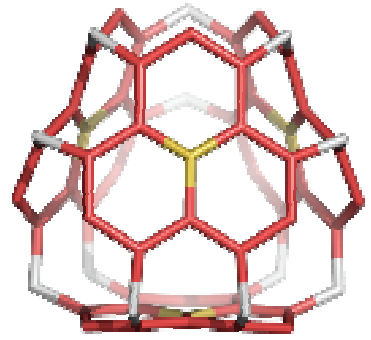

Tri6_T_64Z; Patch: [1:(6) $]$ ]-6-

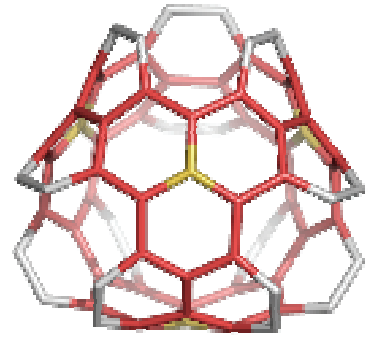

Tri6_T_76A; Patch: [1:(6) 3 ] -8-

Fig. 3. Tetrapodal nanotube junctions with patches: tripentylene, triphenylene and hexagon triples

HOMO-LUMO gaps are comparable while the strain, according to the Haddon's theory [9, 10], is again in favor of these open structures. The HOMA index of aromaticity calculated on patches is not relevant since, e.g Tri6_T_64Z shows a value of 0.636 while its Kekule count is zero (Table 1, line 6) and the strain is the second high, among the tetrapodal units. This index is based more on geometries than electronic distribution (eventually delocalization, which is the most important fact in aromaticity). Even the geometry is forced by the constrains of single bonds C-C, the pi-electrons of such a hexagon-triple "Tri6" patch $\left[1:(6)_{3}\right]$ will not fit to a Kekulé structure. In chemistry it is known that structures that cannot have a Kekulé structure cannot exist as real molecules [11]. In the opposite to the above structure is Triphenylene, a planar polyhex structure, with no strain and maximum HOMA index $[12,13]$ value (in bold - Table 1, line 10), also a Clar $[14,15]$ structure, thus being the most stable molecule in Table 1. The Kekule structure count is also irrelevant to the molecular stability, even some suggestions can be drawn. 
Table 1. Energetics of some tetrapodal nanotube junctions and the reference $\mathrm{C}_{60}$

\begin{tabular}{c|l|c|c|c|c|c}
\hline & \multicolumn{1}{|c|}{ Structure } & E & HL Gap & $\begin{array}{c}\text { Strain/C } \\
\times 10^{3}(\mathrm{kcal} / \mathrm{mol})\end{array}$ & $\begin{array}{c}\text { HOMA } \\
\text { patch }\end{array}$ & $\begin{array}{c}\text { Kekulé } \\
\text { count }\end{array}$ \\
\hline 1 & TriPen_T_60A & -38.092 & 7.191 & 21.873 & -0.455 & 128 \\
\hline 2 & TriPen_TT_84A & -38.028 & 7.043 & 12.004 & -0.401 & 12500 \\
\hline 3 & TriPhen_T_60A & -38.095 & 8.070 & 21.120 & 0.222 & 1944 \\
\hline 4 & TriPhen_TT_84A & -38.029 & 7.762 & 11.696 & 0.283 & 12500 \\
\hline 5 & TriPhen_TT_84Z & -38.023 & 4.815 & 42.630 & 0.493 & 256 \\
\hline 6 & Tri6_T_64Z & -38.082 & 5.824 & 37.971 & $\mathbf{0 . 6 3 6}$ & $\mathbf{0}$ \\
\hline 7 & Tri6_T_7_76A & -38.046 & 6.250 & 11.276 & 0.279 & 2700 \\
\hline 8 & Tri6_T_76A & -38.047 & 5.612 & 19.566 & 0.340 & 9504 \\
\hline 9 & C60 & -37.864 & 7.418 & 137.600 & 0.493 & 12500 \\
\hline 10 & Triphenylene & -38.260 & 10.378 & $\mathbf{0}$ & $\mathbf{0 . 6 7 8}$ & 9 \\
\hline
\end{tabular}

In this respect, compare the structures TriPhen_TT $84 \mathrm{~A} / \mathrm{Z}$ (lines (4 and 5). The A-structure (i.e., the armchair-ended one) shows the higher Kekulé count and better energetic parameters in comparison to the Z-isomer, with Kekulé count by two orders of magnitude less that the A-isomer.

\section{CONCLUSIONS}

The tetrapodal nanotube junction can be modeled by using operations on map, coupled by fullerene spanning. They can self-assembly in more complex structures, like dendrimers and/or multi tori of high genera. Eight tetrapodal units were designed and their energetics evaluated at the Hartree-Fock HF level of theory. Their stability is discussed in terms of total energy, HOMO-LUMO gap, strain energy, HOMA index of aromaticity and the Kekulé structure count. The overall result of this study was that the tetrapodal junctions can be a challenge for the laboratory synthesis of new nanostructures.

\section{Acknowledgments}

The work was supported by the Computational grant No. 133, PCSS (Poznań, Poland).

\section{References}

[1] M.V. Diudea, Cs.L. Nagy, Periodic Nanostructures. Springer, 2007.

[2] M.V. Diudea, Nanomolecules and Nanostructures - Polynomials and Indices. MCM, No. 10, Univ. Kragujevac, Serbia, 2010.
[3] M.V. Diudea, M. Ştefu, P.E. John, A. Graovac, Generalized operations on maps. Croat. Chem. Acta 79, 355-362 (2006).

[4] M. Ştefu, M.V. Diudea, P.E. John, Composite operations on maps, Studia Univ. "Babes-Bolyai" 50, 165-174 (2005).

[5] M.V. Diudea, Nanoporous carbon allotropes by septupling map operations. J. Chem. Inf. Model. 45, 1002-1009 (2005).

[6] M. Stefu, M.V. Diudea, CVNET software. Babes-Bolyai Univ., 2005.

[7] Cs.L. Nagy, M.V. Diudea, Nano Studio software. BabesBolyai Univ., 2009.

[8] Gaussian 09, Revision A.1, M.J. Frisch, G.W. Trucks, H.B. Schlegel, G.E. Scuseria, M.A. Robb, J.R. Cheeseman, G. Scal-mani, V. Barone, B. Mennucci, G.A. Petersson, H. Nakatsuji, M. Caricato, X. Li, H.P. Hratchian, A.F. Izmaylov, J. Bloino, G. Zheng, J.L. Sonnenberg, M. Hada, M. Ehara, K. Toyota, R. Fukuda, J. Hasegawa, M. Ishida, T. Nakajima, Y Honda, O Kitao, H Nakai, T. Vreven, J.A. Montgomery, J.E. Peralta, F. Ogliaro, M. Bearpark, J.J. Heyd, E. Brothers, K.N. Kudin, V.N. Staroverov, R. Kobayashi, J. Normand, K. Raghavachari, A. Rendell, J.C. Burant, S.S. Iyengar, J. Tomasi, M. Cossi, N. Rega, N.J. Millam, M. Klene, J.E. Knox, J.B. Cross, V. Bakken, C. Adamo, J. Jaramillo, R. Gomperts, R.E. Stratmann, O. Yazyev, A.J. Austin, R. Cammi, C. Pomelli, J.W. Ochterski, R.L. Martin, K. Morokuma, V.G. Zakrzewski, G.A. Voth, P. Salvador, J.J. Dannenberg, S. Dapprich, A.D. Daniels, Ö. Farkas, J.B. Foresman, J.V. Ortiz, J. Cioslowski, D.J. Fox (2009) Gaussian Inc Wallingford CT.

[9] R.C. Haddon, J. Am. Chem. Soc. 109, 1676 (1987).

[10] R.C. Haddon, J. Am. Chem. Soc. 112, 3385 (1990).

[11] M. Randić, Aromaticity of Polycyclic Conjugated Hydrocarbons. Chem. Rev. 103, 3449-3605 (2003).

[12] T.M. Krygowski, A. Ciesielski, J. Chem. Inf. Comput. Sci. 35, 203 (1995)

[13] T.M. Krygowski, M. Cyranski, Tetrahedron 52, 1025564 (1996).

[14] E. Clar, Polycyclic Hydrocarbons. Acad. Press, London, 1964.

[15] E. Clar, The Aromatic Sextet. Wiley, New York, 1972. 


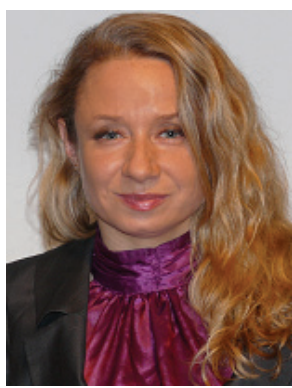

BEATA SzEFLER - Doctor of Chemistry, laboratory diagnostician, adiunkt - researcher in CM UMK in Bydgoszcz, Department of Physical Chemistry, Poland. Graduate of the Medical Academy in Bydgoszcz, Faculty of Pharmacy. Degree: PhD (2010) in Chemical Sciences, University of Technology \& Life Sciences Bydgoszcz, Poland. Experience in Microbiology, Hematology and Pharmacokinetics. Research interests: molecular modeling of aromatic systems, with particular emphasis on the importance of biochemical molecules, study on properties of fullerenes using HF, DFT methods and MD, docking ligandprotein, QSAR. Principal investigator - parameterization of force fields, molecular dynamics simulations of selected protein and ligand-protein systems, quantum-chemical study of small ligands, topological description of electronic structure of ligands (Atoms-in-Molecules methodology), data analysis and participation in the publication process. Member of KIDL - Poland.

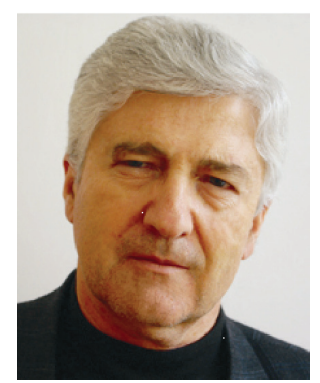

MirceA V. DiudeA - Full Professor at the Department of Chemistry (from 1996), "Babes-Bolyai" University, Cluj, Romania and Head of TOPO GROUP CLUJ. POET. Author of 8 books of poetry, more than 270 scientific articles (Hirsch index 25 (ISI) with more than 1200 citations in ISI journals) and 14 authored or edited books, in three directions: Molecular Topology, QSAR/QSPR and Nanoscience. The scientific activity in his group is supported by 10 original software programs. As didactical activity, he delivered courses of Molecular Topology, QSAR/QSPR and Fullerenes and Nanostructures, basically at Master and $\mathrm{PhD}$ levels (with $15 \mathrm{PhD}$ theses defended so far). Member of International Academy of Mathematical Chemistry (2005), Founding president of European Society of Mathematical Chemistry and member of Editorial Board of: Croatica Chemica Acta, MATCH, Communications in Mathematical and in Computer Chemistry, Internet Electronic Journal of Molecular Design, Carpathian Journal of Mathematics, Iranian Journal of Mathematical Chemistry, Acta Universitas Cibiniensis and Senior Editor at International Journal of Chemical Modeling, NOVA Publishers, New York, USA. 